\title{
Entre la autonomía y la subordinación: gobiernos y parlamentos en los espacios locales. El caso de la provincia argentina de Córdoba entre 1890 y 1930
}

\author{
Between autonomy and subordination: \\ Governments and parliaments in local areas. The case of the \\ Argentine province of Córdoba between 1890 and 1930
}

Javier Moyano*

RESUMO

Mi objetivo es contribuir, a partir del análisis de la provincia argentina de Córdoba, a la discusión sobre el grado de autonomía de los órganos legislativos respecto a los gobiernos en regímenes políticos fundados en el falseamiento electoral o en etapas de transición hacia ordenamientos más abiertos y competitivos. En función de ello, procuraré distinguir factores y circunstancias cambiantes que incidían sobre las decisiones de los representantes parlamentarios. El período que abarca la investigación incluye desde los primeros cuestionamientos de peso, a partir de la revolución de 1890, al régimen oligárquico instaurado en Argentina tras la elección presidencial de Julio A. Roca en 1880, hasta la crisis política que en 1930 puso fin a la experiencia democrática iniciada luego de la reforma electoral que, con la sanción de la denominada ley Sáenz Peña, en 1912 introdujo garantías a la competencia electoral mediante la instauración del sufragio secreto y obligatorio, y la adopción de los padrones militares como registro de votantes.

PALAVRAS-CHAVE: autonomía; subordinación; gobierno; parlamento.

\section{ABSTRACT}

My goal is to contribute to the analysis of the Argentine province of Córdoba, the discussion about the autonomy of the legislature with regard to governments in political systems based on electoral distortion or stages of transition towards more open systems and competitive. Accordingly, try to distinguish factors and changing circumstances that impact on the decisions of the parliamentary representatives. The period covered includes research from the first issue, from the revolution of 1890 , the oligarchic regime in place in Argentina's presidential election after Julio A. Roca in 1880 until the political crisis in 1930 that ended the democratic experiment that began after the electoral reform, with the sanction of the law called Sáenz Peña, introduced in 1912 guarantees the competition through the introduction of electoral suffrage and secret mandatory, and the adoption of the standards as a military voter registration.

KEYWORDS: autonomy; subordination; government, parliament.

En las últimas décadas, numerosos estudios han concentrado su atención sobre el desarrollo de las formas representativas en la historia latinoamericana, incluso durante los llamados regímenes oligárquicos o notabiliares del siglo XIX $\mathrm{y}$ principios del XX, o bien durante etapas de transición hacia ordenamientos

Doutor em História por El Colegio de México (Colmex). Professor da Universidad Nacional de Córdoba (UNC) / Argentina. 
Entre la autonomía y la subordinación: gobiernos y parlamentos en los espacios locales...

más cercanos a la democracia universal. ${ }^{1}$ En ese marco, las relaciones entre órganos legislativos y gobiernos revisten fundamental relevancia para analizar la naturaleza de los gobiernos representativos. Preocupación clásica en tradiciones historiográficas como la norteamericana, ${ }^{2}$ diversos trabajos sobre América Latina también han prestado especial atención a esta temática. 3

En este artículo, mi objetivo es contribuir, a partir del análisis de la provincia argentina de Córdoba, a la discusión sobre el grado de autonomía de los órganos legislativos respecto a los gobiernos en regímenes políticos fundados en el falseamiento electoral o en etapas de transición hacia ordenamientos más abiertos y competitivos. En función de ello, procuraré distinguir factores y circunstancias cambiantes que incidían sobre las decisiones de los representantes parlamentarios. El período abarcado por la investigación incluye desde los primeros cuestionamientos de peso, a partir de la revolución de 1890, al régimen oligárquico instaurado en Argentina tras la elección presidencial de Julio A. Roca en el año 1880,4 hasta la crisis política que en 1930 puso fin a la experiencia democrática iniciada luego de las reformas electorales que, con la sanción de la denominada ley Sáenz Peña en el nivel federal y de una reforma constitucional en el caso cordobés, en 1912 introdujeron garantías a la competencia electoral mediante la instauración del sufragio secreto y obligatorio, y la adopción de los padrones militares como registro de votantes.

Sostendré, a modo de hipótesis, que, antes de la sanción de la ley Sáenz Peña y de la reforma constitucional cordobesa que en 1912 adaptó la carta magna provincial a la nueva normativa federal en materia de elecciones, la

\footnotetext{
1 A título de ejemplo, esta temática constituye una de las principales preocupaciones en las compilaciones realizadas por Carlos Malamud (1995 y 2000), Hilda Sábato (1999) e Hilda Sábato y Alberto Lettieri (2003).

2 Según se aprecia, por ejemplo, en estudios de historia política regional como los llevados adelante por Thomas Holt (1979) y por Lacy Ford (1984 y 1988) acerca del estado de Carolina del Sur en el siglo XIX.

3 Tal como puede notarse, entre otros trabajos, en los análisis efectuado por Marcello Carmagnani (1994) sobre las articulaciones entre Estado y mercado en el México porfirista; y por María Luna Argudín (1971) sobre el parlamento mexicano entre la victoria liberal en 1857 y el fin del porfiriato en 1910.

4 Entiendo por régimen oligárquico a un tipo de régimen en el cual el control no era ejercido por los ciudadanos sobre los gobernantes sino a la inversa, ya que, aunque eran resultado de complejas negociaciones dentro del grupo más o menos reducido que ocupaba el gobierno, los comicios se trastocaban en "designación", mediante fraude y coerción, de las nuevas autoridades por sus antecesores, convertidos en "gobiernos electores". En función de la capacidad del gobierno de concentrar los recursos, antes dispersos entre diversos actores, conducentes al fraude electoral, considero que el régimen oligárquico argentino se inició con la primera presidencia de Julio A. Roca en 1880 (ANSALDI, 1992: 44-47 y BOTANA, 1994: 69-78).
} 
relación entre legislatura y gobierno provincial era de mediana autonomía y de mediana subordinación, y ello se debía a la capacidad del ejecutivo de garantizar la elección y reelección de los representantes, y a la posibilidad del parlamento local, a partir de diversas atribuciones que concentraba, de condicionar la gestión de gobierno. La autonomía de los espacios legislativos podía crecer al punto de obstruir al gobierno, situación que podía ser favorecida, entre otros factores, por la limitación temporal de los mandatos ejecutivos, la inestabilidad de las alianzas oficialistas y las escisiones entre autoridades federales y provinciales.

La reforma electoral de 1912 potenció, al instaurar mayores garantías a la competencia política y establecer el sistema de lista incompleta por el cual la primera minoría obtenía un tercio de los escaños que se ponían en juego en cada elección, una más nutrida presencia parlamentaria de la oposición, lo cual, en ocasiones, podía traducirse en alineamientos divergentes entre ejecutivo y mayoría legislativa. Asimismo, la pertenencia a un mismo partido por parte del titular del ejecutivo y de la mayoría de los legisladores ya no implicaba, necesariamente, que estos últimos respondieran a la liga interna del gobernador, quien muchas veces no controlaba los órganos partidarios a cargo de nominar candidatos.

\section{El gobierno y la Legislatura durante el régimen oligárquico (1890- 1912). ¿Autonomía o subordinación de los órganos parlamentarios?}

En oposición a la pretensión de sobrestimar el poder del gobierno en su relación con el parlamento, diversos autores han destacado la autonomía de los congresistas en el régimen político argentino anterior a la reforma electoral de 1912. Mientras Carlos Malamud hace notar la escasa disciplina partidaria de los legisladores durante esa etapa, Lee Kress señala que los parlamentarios muchas veces votaban libremente. Peter Smith, por su parte, sostiene que las alianzas en el Congreso no eran permanentes. En tanto, Natalio Botana y Paula Alonso coinciden en que no podía darse por descontado el apoyo parlamentario al ejecutivo. Joan Supple considera, en su análisis sobre la provincia de Mendoza, que hubo prolongadas etapas en que el legislativo no fue controlado por el oficialismo provincial (ALONSO, 2000: 51; BOTANA, 1994: 103; KRESS, 1972: 
124; MALAMUD, 2000: 108; SMITH, 1974: 47; y SUPPLE, 1988: 84-87 y 393).

También se ha señalado que las bancas legislativas eran armas relevantes para la lucha política, pues permitían actuar en ámbitos propicios para el establecimiento de alianzas, e influir sobre la opinión pública. Al respecto, Botana sostiene que el senado nacional era un ámbito favorable para la comunicación entre oligarquías provinciales, mientras que Alonso destaca el impacto público que tenían las interpelaciones a ministros, y afirma que los debates parlamentarios alcanzaban resonancia en la prensa. Como analiza Anne Potter, también era posible presionar al ejecutivo a partir de atribuciones parlamentarias en asuntos -como las leyes de presupuesto e impuestosdecisivos para la gestión de gobierno; o bien -como en el caso de la aprobación, excepto durante los meses de receso parlamentario, de intervenciones federales a las provincias- para el mantenimiento del orden y/o de las posiciones de poder de la alianza gobernante (Alonso, 2000: 233-242; Botana, 1994: 114; Potter, 1979).

En Argentina, hubo momentos en que el parlamento y el gobierno discreparon en cuestiones fundamentales para la resolución de disputas de poder. Paula Alonso cita casos, en referencia al Congreso Nacional en la primera mitad de la década de 1890 , en que la independencia parlamentaria conspiró contra la continuidad de los titulares del poder ejecutivo 5 . Cuando, luego de 1904, el Partido Autonomista Nacional (en adelante PAN), gobernante desde 1880 y liderado por Julio A. Roca, resignó la presidencia de la nación en manos de un dudoso aliado, el ex opositor Manuel Quintana, la mayoría legislativa roquista, dependiente de elecciones provinciales, fue un arma defensiva hasta la disolución del congreso decretada en 1908 por el presidente José Figueroa Alcorta, dirigente cordobés que ocupó la titularidad del ejecutivo federal tras la muerte de Quintana en 1906. Antes del cierre del parlamento, los roquistas, si bien consideraban que esa mayoría debía ser usada con cautela, estaban dispuestos a resistir en el Congreso Nacional si el gobierno se mostraba

\footnotetext{
5 Se trata del retiro de apoyo parlamentario que, respectivamente, definió las renuncias de los presidentes Miguel Juárez Celman, en 1890, y Luis Sáenz Peña, en 1895 (ALONSO, 2000: 231232). Considero, sin embargo, que esta hipótesis de Alonso sobre la autonomía parlamentaria en asuntos directamente vinculados con la preservación de las posiciones detentadas por el ejecutivo federal, se funda, casi exclusivamente, en situaciones excepcionales en que los presidentes se habían enfrentado con sus antecesores en el cargo y afrontaban una fuerte impugnación de actores ajenos a los espacios parlamentarios.
} 
amenazante. A mediados de 1905, un dirigente del PAN opinaba que “... nuestra situación política como miembros del Partido Nacional, es muy difícil porque toda insinuación o indicación parlamentaria para modificar en algo los proyectos del gobierno, es explotada ante el presidente...”. Sin embargo, un año más tarde, cuando el presidente Figueroa Alcorta designaba ministro del interior al roquista Joaquín V. González en un intento momentáneo de acercar posiciones, un político roquista afirmaba que "hemos vencido al presidente en el Congreso”. Cuando tres meses más tarde González renunciaba a su cargo, ese mismo dirigente aseveraba que "vuelve la mayoría parlamentaria de ambas cámaras a ponerse de frente contra esta reincidencia...”. ${ }^{6}$ Es posible apreciar que, en ciertas circunstancias, la posibilidad de actuar con mediana autonomía otorgaba protagonismo a los legisladores en las luchas de poder a escala nacional.

¿Cómo eran, en ese contexto, las relaciones entre el gobierno y la legislatura en la provincia de Córdoba? Esta provincia fue gobernada por el roquista PAN hasta 1909 y por una coalición alineada con Figueroa Alcorta luego de esa fecha. En efecto, agrupados en el PAN, los roquistas obtuvieron el control del gobierno provincial luego de que la resolución de la revolución de 1890 desplazara a los juaristas, antiguos aliados con los cuales se habían enemistado en la segunda mitad de la década de 1880. Esa posición fue mantenida durante casi dos décadas, aunque hubo ocasiones en que el roquismo debió ceder la titularidad del ejecutivo a dirigentes eventualmente aliados pero ajenos al PAN. En 1909, los roquistas fueron desalojados del gobierno por una intervención federal que allanó el camino a la gobernación a una nueva coalición alineada con el oficialismo nacional.

En ese marco, en Córdoba el poder de algunos legisladores nacionales se fundaba, en parte, en su papel de mediadores entre los actores locales y el gobierno federal. Siendo diputados en 1900, el ex gobernador Eleazar Garzón y el dirigente José Yofre eran portavoces del gobernador Donaciano del Campillo (1898-1901) ante el presidente Julio A. Roca. En 1911, el diputado Manuel Peña actuaba como nexo entre el nuevo presidente Roque Sáenz Peña (1910-1914) y políticos cordobeses que adherían al oficialismo federal. Según su propio

6 Archivo General de la Nación (en adelante AGN), Fondo Julio A. Roca s./f.; Fondo Felipe Yofre, agosto de 1905; septiembre y diciembre de 1906. 
Entre la autonomía y la subordinación: gobiernos y parlamentos en los espacios locales...

testimonio, el diputado Ramón J. Cárcano era intermediario en conversaciones entabladas entre Sáenz Peña y el gobernador Félix T. Garzón (1910-1913) a principios de la década de 1910. Si bien su posición no se debía sólo al cargo ocupado pues, entre otros factores, en muchos casos también se trataba de ex gobernadores, algunos parlamentarios federales lideraban ligas internas dentro del oficialismo cordobés, y muchas veces se encontraban entre los principales negociadores en las sucesiones gubernativas que tenían lugar cada tres años. Fueron los casos, en 1900, de los ex gobernadores Julio Astrada y Eleazar Garzón, quienes conseguían ser reelectos en sus bancas, además de cargos ministeriales y escaños legislativos para sus aliados internos. A fines de 1906 sucedía lo mismo con Julio A. Roca (h.) y Jerónimo del Barco. El primero establecía, a partir del apoyo que daba a su candidatura, una sólida alianza con el nuevo gobernador José Ortiz y Herrera (1907-1909), quien en 1908 defendía la reelección de Roca como diputado nacional. Del Barco, alineado con el gobierno federal que en 1906 acordaba con la candidatura gubernativa de Ortiz y Herrera, conseguía ser vicegobernador y, meses más tarde, ingresaba nuevamente a la cámara baja nacional.7

La legislatura cordobesa estaba conformada por una cámara de senadores compuesta con 25 miembros, representantes de otros tantos departamentos, y una cámara de diputados con 32 integrantes, elegidos, mediante el sistema de lista completa, por circunscripciones que, excepto en el caso del más poblado departamento Capital, agrupaban a varios distritos. Las cámaras reproducían, en la arena provincial, algunos rasgos del congreso federal en lo atinente a su relación con el ejecutivo. En un marco ideológico en que la pluralidad de opiniones en el parlamento era considerada un valor positivo, ${ }^{8}$ muchos legisladores actuaban con autonomía respecto de los gobiernos. Cuando ello ocurría, los representantes no sólo alcanzaban protagonismo en función del modo en que votaban en el recinto. Con el fin de influir sobre la opinión pública, también contaba comunicar, mediante la prensa, el presunto apoyo de la

\footnotetext{
7 AGN, Fondo Figueroa Alcorta, febrero y marzo de 1908; Fondo Miguel Juárez Celman, noviembre de 1906; Fondo Julio A. Roca, mayo de 1900; Fondo Felipe Yofre, diciembre de 1906; La Carcajada (8 y 15/07/1900); La Libertad (18/03/1900; 15 /03/1901; 5/08 y 6/12/1903; y 2/08/1906); La Patria (4/03/1903); La Voz del Interior (13/12/1911); y Ramón J. Cárcano (1945: capítulos 3.III, 4.I y 5.I).

8 A juzgar, por ejemplo, por críticas vertidas, en 1908, por sectores católicos, quienes sostenían que había en la legislatura una "unanimidad vergonzosa... donde no cabe un hombre que no sea llevado por el oficialismo". Los Principios (8/01/1908).
} 
tribuna en los debates. Por ejemplo, en 1900, ante una interpelación al ministro de gobierno, promovida por un grupo de legisladores opositores, tanto los partidarios del oficialismo como quienes defendían a los interpelantes se atribuían los aplausos de los espectadores. 9

La legislatura podía actuar con independencia y condicionar decisiones del ejecutivo pero, dada la concentración de muchos recursos de poder en manos de los gobernadores, los factores que definían la obtención de escaños limitaban esa autonomía y esa capacidad. La nominación oficialista de candidatos a legisladores era una atribución de las juntas partidarias, controladas por los gobernadores, de quienes también dependía, generalmente, el triunfo electoral en función de la incidencia ejercida por policías y jefes políticos. Esa capacidad de los gobernadores de influir sobre las nominaciones partidarias se aprecia en la correspondencia de los dirigentes. En 1900, por ejemplo, un legislador provincial solicitaba al presidente Roca que intercediera ante el gobernador Del Campillo para poder ser reelecto. En 1905, en tanto, rivales del gobernador José V. de Olmos (1904-1907) reconocían el papel central que éste ejercía en la definición de candidaturas, cuando le reclamaban escaños para sus aliados. ${ }^{10} \mathrm{Si}$ esos mecanismos fallaban y políticos opositores ganaban comicios, las cámaras legislativas, mayoritariamente oficialistas, podían rechazar sus diplomas, ${ }^{11}$ como sucedía tras las elecciones parlamentarios de 1900 y $1907 .{ }^{12}$ De ese modo, las posibilidades de acceso a un escaño estaban condicionadas por las decisiones del gobernador. Como señala Carlos Melo en su análisis sobre el régimen político argentino anterior a 1912, la oposición sólo obtenía asientos parlamentarios cuando acordaba con el gobierno (1970: 283).

La incidencia gubernativa en la asignación de escaños no siempre implicaba que los compromisos perdurarían posteriormente. Por ejemplo, luego

9 AGN, Fondo Julio A. Roca, junio de 1900.

10 AGN, Fondo Julio A. Roca, enero y junio de 1900; Fondo Felipe Yofre, marzo de 1905.

11 Sobre la utilización con fines partidistas de esa atribución parlamentaria, es sugerente el análisis de Guerra sobre las primeras elecciones que tuvieron lugar en México tras la caída de Porfirio Díaz (1994).

12 Archivo de la Honorable Legislatura de la Provincia de Córdoba (en adelante AHL), Senadores (22/05/1907); Diputados (25/04/1907); La Libertad (2/06/1900); Los Principios (18/07/1907). 
Entre la autonomía y la subordinación: gobiernos y parlamentos en los espacios locales...

de 1904, mientras los denominados conservadores reformistas ${ }^{13}$ ganaban espacios en el gobierno federal en desmedro del roquismo, crecían las fugas de legisladores nacionales y provinciales electos con el patrocinio del gobierno provincial, de filiación roquista, hacia las camarillas alineadas con el oficialismo federal. Entre otros, el ex gobernador Eleazar Garzón (1890-1892) y el ex intendente capitalino Jerónimo del Barco (1900-1902) cambiaban su alineamiento mientras ocupaban escaños federales en las mencionadas circunstancias. El gobierno local tenía, sin embargo, capacidad para disciplinar a los legisladores, pues sus candidaturas no sólo eran tributarias del patrocinio oficialista. La posibilidad de reelección dependía de similares factores, y ello era comprobado por quienes pasaban a la oposición, y por dirigentes oficialistas distanciados del gobernador. Por ejemplo, de un total de quince legisladores que, alineados bajo el liderazgo del ex gobernador (1895-1898) y futuro presidente José Figueroa Alcorta, en 1900 había abandonado las filas del gobernante PAN, sólo uno mantenía su cargo tras terminar su mandato, mientras que, en 1905, se frustraba la reelección de legisladores alineados con el senador nacional roquista Felipe Yofre, quien, dada su pretensión de preservar su banca al concluir su mandato, rivalizaba con el también roquista gobernador José V. de Olmos, dirigente que aspiraba a ingresar a la cámara alta federal al termino de su gestión al frente del ejecutivo provincial. Asimismo, en 1907, el diputado Arturo Domínguez, quien había rivalizado permanentemente con el oficialismo en la cámara baja, se postulaba a la reelección como candidato opositor por el norteño departamento Río Seco, pero era derrotado por el postulante del gobierno. Por otro lado, las promesas de reelección a cambio de apoyo parlamentario a las posiciones del gobierno no habrían sido una práctica desconocida antes de 1912, e, incluso, un diputado oficialista, el roquista Rafael Núñez, denunciaba hechos de ese tipo en 1907.14

Esos expedientes fracasaban en casos particulares y muchas veces había minorías opositoras en la Legislatura. Por ejemplo, en la asamblea legislativa que, en 1904, se reunió para designar senador nacional, la oposición presentó un candidato, el cual fue derrotado ampliamente por el oficialismo. La victoria

13 Sector de los grupos gobernantes que, sucesivamente alineado con los presidentes Manuel Quintana, José Figueroa Alcorta y Roque Sáenz Peña, promovía una apertura del régimen político confrontando con los seguidores de Julio A. Roca.

14 AGN, Fondo Felipe Yofre, diciembre de 1905; AHL, Diputados (14/02 y 25/04/1907). 
gubernista se debía a que los recursos en manos del ejecutivo casi siempre alcanzaban para garantizar una amplia mayoría a sus partidarios. Incluso cuando, en 1900, la fuga a la oposición de un sector, alineado con el ex gobernador José Figueroa Alcorta, modificó la mayoría en la cámara baja provincial, presiones del presidente Roca revertían esa correlación de fuerzas, pues parte de los diputados rebeldes aceptaban subordinarse al gobernador Donaciano del Campillo. En su correspondencia con Roca, diputados disidentes que retornaban al oficialismo se mostraban incondicionalmente dispuestos a seguir el liderazgo de Campillo tras la indicación del presidente en ese sentido, e incluso votaban por el rechazo de diplomas de otros disidentes que habían sido electos legisladores. ${ }^{15}$ Como en otros países, ${ }^{16}$ la autonomía del electo no alteraba la mayoría aplastante que, de todos modos, el oficialismo casi siempre garantizaba. ${ }^{17}$

El gobierno tenía medios para conseguir la adhesión mayoritaria de la legislatura, y por ello el obstruccionismo parlamentario fue excepcional en Córdoba. Pero tales excepciones podían ocurrir. En el caso ya citado de 1900, hubo mayorías opositoras susceptibles de ser presionadas por el gobierno. También actuaron, en otros momentos, mayorías opositoras decididas a desplazar al gobernador, como aquellas que en 1888 destituyeron al gobernador Ambrosio Olmos (1886-1888) por medio de un juicio político; o bien mayorías opositoras resueltas a obstruir la gestión del ejecutivo. En 1893, por ejemplo, el gobernador Manuel Pizarro, enfrentado con la mayoría legislativa, se veía obligado a dimitir al no encontrar apoyo de las cámaras a su gestión. Podían surgir, además, mayorías parlamentarias oficialistas pero independientes del gobernador en asuntos que generaban crisis en las alianzas gobernantes. Era el caso de las camarillas que, entre 1910 y 1913, se alineaban en el entonces gobernante Partido Constitucional y reconocían el liderazgo del gobernador Félix T. Garzón, pero tomaban decisiones, como el rechazo de diplomas de

\footnotetext{
15 AGN, Fondo Julio A. Roca, julio de 1900.

16 José Murilo de Carvalho señala que, en Brasil, los gobernadores intervenían en comicios para garantizar la mayoría legislativa, la cual debía ser amplia para reducir los efectos de las disidencias (1987: 150).

17 Este juicio es coincidente con el análisis de Lee Kress sobre la política nacional en la década de 1880 . Kress reconoce que los legisladores muchas veces votaban libremente, pero advierte que el congreso seguía mayoritariamente el liderazgo de la administración (1972: 228).
} 
legisladores electos encolumnados en ligas internas rivales, que resentían las posibilidades de continuidad de la alianza oficialista.

¿Cuáles eran las condiciones que alteraban la capacidad del ejecutivo de controlar las cámaras? El límite temporal de los cargos ejecutivos, la inestabilidad de las alianzas entre camarillas y/o las escisiones entre oficialismo federal y provincial, contribuían a que la legislatura tomara distancia del gobierno. Veamos algunos ejemplos.

La destitución, en 1888, del gobernador Ambrosio Olmos por la legislatura provincial tuvo lugar en un escenario que combinaba el creciente distanciamiento entre los gobiernos provincial y federal con la debilidad de un primer mandatario que había accedido a su cargo a partir de un compromiso por el cual se asignaba a circunstanciales aliados la mayoría en las cámaras. La autonomía de los parlamentarios se fortalecía, en este caso, porque había cargos ejecutivos, incluida la jefatura de policía, relevantes a la hora de fabricar elecciones, que habían quedado en manos de rivales de Olmos en virtud de los acuerdos que lo habían llevado a la primera magistratura. En 1893, la inestabilidad de las alianzas era causa del retiro de apoyo parlamentario al gobernador Manuel Pizarro, quien por ello renunciaba a su cargo. Pizarro no pertenecía al oficialista PAN que, al promover su candidatura gubernativa en 1892, se había reservado la mayoría legislativa. La inestabilidad de los acuerdos se combinaba con el límite temporal de los mandatos gubernativos cuando, en 1900, surgía una mayoría opositora en la cámara baja provincial. En esa ocasión, la mayor parte de los diputados opositores habían sido electos durante la gestión del anterior gobernador José Figueroa Alcorta, quien luego se distanciaba de las nuevas autoridades provinciales. El cambio en la correlación de fuerzas a escala nacional podía modificar los alineamientos de muchos legisladores provinciales y, en consecuencia, podía alterar la mayoría en las cámaras. En 1909, cuando el gobierno federal se decidió a atacar al gobierno cordobés, la mayoría legislativa oficialista devino rápidamente opositora, pues muchos legisladores buscaban reacomodarse ante eventuales cambios en la correlación de fuerzas en el interior de los grupos gobernantes. Tales legisladores se negaron a dar quórum a las cámaras durante varios meses. De ese modo allanaron, al generar con tal comportamiento una crisis institucional, el camino a la intervención federal que desalojó al roquismo del gobierno 
Entre la autonomía y la subordinación: gobiernos y parlamentos en los espacios locales...

provincial. $^{18}$

Entre 1910 y 1912, el ejecutivo aun garantizaba electoralmente la mayoría legislativa, pero las alianzas eran más inestables tras el desplazamiento del PAN del gobierno provincial. En 1910 llegó al gobierno una coalición que, con apoyo de una intervención federal, obtuvo la totalidad de los escaños puestos en juego en los comicios parlamentarios. Sumados a los legisladores que, designados previamente, habían fugado desde el anterior hacia el nuevo oficialismo, la mayoría en las cámaras fue amplia, pero la alianza se disolvía rápidamente. ${ }^{19}$ Las camarillas que permanecieron oficialistas eran mayoritarias en la legislatura, pero no respondían de modo incondicional al gobernador. Los senadores pertenecientes a una liga oficialista solían tejer alianzas con grupos que habían pasado a la oposición, conformando otra mayoría que, por momentos, adoptaba prácticas obstruccionistas contra el ejecutivo. La liga oficialista rival controlaba las fuerzas policiales, recurso imprescindible para la fabricación de elecciones. En los comicios parlamentarios de 1912, esta última liga conseguía mayoría propia en ambas cámaras, pero sus adversarios recurrían al rechazo de diplomas. ${ }^{20}$ Un expediente muchas veces utilizado por las alianzas gobernantes para garantizar el control de los órganos parlamentarios, se empleaba ahora para impedir que una liga oficialista alcanzara una posición predominante.

Como ya adelanté, la relación de mediana autonomía y mediana subordinación entre legislatura y gobierno provincial se debía a la capacidad del ejecutivo de garantizar la elección y reelección de los representantes, y a la posibilidad de condicionar al gobierno por parte del parlamento, cuyos miembros no siempre mantenían, tras ingresar a las cámaras, sus compromisos con las autoridades que habían promovido sus postulaciones. La autonomía podía crecer al punto de obstruir al gobierno. Para ello influían la limitación temporal de los mandatos ejecutivos, la inestabilidad de las alianzas oficialistas

18 La Libertad (12/04 al 20/08/1909); La Nación (14/04/al 20/05/1909); La Patria (14/05 al 20/o8/ 1909); Emilio Sánchez (1986: 246-249 y 333-338); y Cristina Vera de Flachs (1986: 10).

19 No se trata de una particularidad del caso en estudio. Por ejemplo, las escisiones partidarias como causa de fragmentación de las mayorías parlamentarias es destacada por Artola en su análisis sobre España durante los últimos años de la restauración (1991: 359-360).

20 AHL, Senadores (11/06/1912); El Comercio (12/06/1912); La Justicia (12/06/1912); La Libertad (12/06/1912); La Voz del Interior (7/05 y 12/05/1912); Los Principios (12/06/1912). 
y las escisiones entre autoridades federales y provinciales.

\section{Gobierno y Legislatura luego de 1912. Convergencia y divergencia entre el ejecutivo y la mayoría parlamentaria}

La reforma electoral de 1912 tuvo varias consecuencias en lo relativo al margen de maniobra de diferentes actores en la lucha política. Por un lado, se reducía la incidencia de quienes controlaban instancias estatales. Por otro, ese control se repartía entre diversas fuerzas políticas, dentro de las cuales, en mayor o menor medida, tenía lugar un proceso de mediana renovación de los elencos dirigenciales. ${ }^{21}$ Tanto a nivel nacional como provincial, una de las principales consecuencias de esa nueva situación fue que, luego de 1912, la relación entre gobiernos y parlamentos fue modificada por una más nutrida presencia de la oposición en las cámaras. En ocasiones, esa presencia se traducía en alineamientos divergentes entre ejecutivo y mayoría legislativa.

En ese contexto de mayor dispersión del control de recursos de poder, la incidencia del congreso nacional en asuntos locales aumentaba si la mayoría de sus integrantes no pertenecían al mismo partido que las autoridades provinciales, pues, en esos casos, quienes cometían fraude, en la medida en que aun era posible hacerlo, no controlaban todas las instancias que juzgaban la validez de los comicios. Por ejemplo, en 1917, con el radicalismo gobernando la provincia, demócratas ${ }^{22}$ y radicales disidentes se unían en el parlamento federal para rechazar el diploma de un diputado electo, alineado con el oficialismo cordobés. Mayor continuidad hubo, en cambio, en el tipo de actuación de congresistas nacionales cordobeses en tanto intermediarios entre actores locales y federales, aunque ahora no sólo comunicaban a fuerzas oficialistas. Por ejemplo, según fuentes roquistas, tres congresistas eran intermediarios en

21 Se trata, en este último caso, de una cuestión relevante, pues en la carrera de los dirigentes cobraba progresiva importancia la trayectoria en el interior de partidos incipientemente orgánicos, y ello incidía sobre las posiciones adoptadas por los legisladores electos ante los asuntos que dividían aguas en la agenda parlamentaria. Sin embargo, aunque sin dejarla de lado totalmente, en este trabajo no me he concentrado en la consideración de esta variable en el análisis de los cambios y continuidades en las relaciones entre gobiernos y parlamentos. Acerca del proceso de recambio en los elencos políticos de la provincia a partir de 1916, véase Marcela Ferrari (2008) y mi trabajo (2006: Capítulo II: "Los dirigentes políticos").

22 A partir de 1914, el Partido Demócrata agrupó a dirigentes y camarillas que, antes de la sanción de la ley Sáenz Peña, habían integrado alianzas gobernantes o partidos de oposición eventualmente cooptables por el oficialismo. 
Entre la autonomía y la subordinación: gobiernos y parlamentos en los espacios locales...

conversaciones que definían el ingreso al radicalismo de camarillas con pasado en otras fuerzas políticas. ${ }^{23}$

A partir de una mayor dispersión del control de recursos de poder, en la provincia de Córdoba, el alineamiento del ejecutivo y la mayoría parlamentaria podía ser coincidente o divergente. Por ejemplo, cuando gobernó el Partido Demócrata (entre 1914 y 1916, y entre 1919 y 1928), por momentos tuvo mayoría legislativa y por momentos no. Mientras tuvo mayoría, en ocasiones ésta fue amplia, aún cuando, como ocurría, por ejemplo, tras los comicios de 1920, el desempeño electoral de radicales y demócratas era equilibrado. ${ }^{24}$ Ello se debía, en el caso de la cámara baja, a que el sistema de lista incompleta distorsionaba su composición en el momento de traducir votos en bancas. En efecto, entre 1912 y 1924, la provincia se dividía en diez circunscripciones que designaban tres o cuatro diputados según el caso, de los cuáles uno sólo era acordado a la minoría. Luego de 1924, se tomaba a la provincia como distrito único para elegir 36 diputados, dos tercios de los cuales correspondían a la agrupación vencedora, independientemente de la cantidad de sufragios cosechados. Por su parte, antes de 1924 la representación de cada uno de los veinticinco departamentos en el senado aun era uninominal. Tras la reforma constitucional de 1923, el número de senadores se amplió a 29, al otorgarse representación ponderada a los departamentos más poblados.

La mayoría oficialista fue contundente entre 1921 y 1924, cuando, luego de que los radicales optaron por la abstención electoral y renunciaron a sus bancas, los demócratas se impusieron con amplitud a débiles agrupaciones rivales socialistas e independientes-25 en todos los distritos. Incluso en algunos departamentos los partidarios del oficialismo habrían seguido, si se da crédito a denuncias parlamentarias y periodísticas, estrategias de "desdoblamiento" que les otorgaron también la representación por la minoría. ${ }^{26}$ Entre 1925 y 1928, luego de que el radicalismo dejara de lado su política abstencionista, los

23 AGN, Fondo Julio A. Roca (h.), octubre de 1912.

24 AHL, Senadores (19/04/1920); Diputados (30/04/1920).

25 AHL, Senadores (25/04/1924); La Voz del Interior (19 y 23/03/1921; 16/02 al 26/03/1924).

26 En la prensa y en el parlamento se denunciaba que la participación de listas aparentemente opositoras respondía a una estrategia de los demócratas para quedarse con la representación por mayoría y minoría. AHL, Senadores (29/04/1921; y 25/04/1924); Diputados (28/04/1921); La Voz del Interior (16/02 al 26/03/1924). 
Entre la autonomía y la subordinación: gobiernos y parlamentos en los espacios locales...

demócratas gobernaron con minoría en la cámara baja. ${ }^{27}$

El oficialismo demócrata debía afrontar el obstruccionismo de sus rivales cuando no tenía mayoría legislativa, y ello era más frecuente y podía ser más prolongado que en la etapa anterior a 1912, si bien en los efectos del obstruccionismo legislativo se advierten significativas líneas de continuidad respecto a aquella etapa. Entre 1925 y 1927, la mayoría radical en la cámara baja puso a la provincia al borde de la intervención federal al negarse a otorgar quórum durante meses. ${ }^{28}$ Como en las circunstancias previas a la mencionada intervención federal de 1909, tal conducta impedía el funcionamiento institucional.

El radicalismo gobernó la provincia de Córdoba entre 1916 y 1919, y entre 1928 y 1930. En la primera etapa mencionada, cuando la imposibilidad de preservar compromisos preelectorales y el transfuguismo de muchos dirigentes adquirieron dimensiones aún más dramáticas que en el período anterior a 1912,29 hubo momentos en que los demócratas, aliados con radicales disidentes, imponían mayoría en las cámaras. A fines de 1916, por ejemplo, demócratas y radicales disidentes asumieron posiciones comunes en varias interpelaciones a miembros del poder ejecutivo. En esas circunstancias, la legislatura fue un arma defensiva frente a un gobierno proclive, según sus críticos, a perseguir al adversario, práctica efectiva para el oficialismo cuando controlaba todos los espacios institucionales, pero contraproducente si sus rivales podían recurrir al obstruccionismo legislativo. El gobierno provincial, en manos de un sector del radicalismo, procuró revertir esa situación. En 1917, una intervención federal, luego de que el gobernador Julio Borda (1917-1919) clausurara el senado, contribuía a modificar parcialmente la composición de las cámaras. El interventor federal aprobaba la incorporación de candidatos oficialistas, o aliados del oficialismo, triunfantes con diplomas demorados, pero también permitía el ingreso a las cámaras de miembros del partido gobernante que habían sido vencidos por los demócratas. Sumadas las consecuencias de esas medidas con el resultado de los comicios legislativos de 1918, el oficialismo

27 AHL, Senadores (4/05/1925; y 30/04/1927).

28 AHL, Senadores (4/05/1925; y 16/04/1926); La Voz del Interior (8/07 al 28/08/1925; 27/o4 al 29/061926; y 10 mar. 1927); y César L. Mansilla (1983: 105-106).

29 Pues el nuevo oficialismo fue incapaz de preservar la lealtad de amplios segmentos del radicalismo, lo cual condujo a una temprana escisión del partido gobernante. 
radical mejoraba su presencia parlamentaria, aunque sin lograr mayoría absoluta. Por ejemplo, en la asamblea legislativa que en 1918 se reunió para designar senador nacional, había veinticuatro parlamentarios oficialistas, veintidós demócratas, seis radicales disidentes y dos "independientes" aliados al oficialismo. Pero además de ser insuficiente, a diferencia de la situación anterior a 1912, para alcanzar el control pleno de los órganos legislativos, manipular la composición del parlamento podía tener efectos negativos para el partido gobernante pues, unido a otras dificultades que el oficialismo afrontaba -falta de respuesta ante los conflictos sociales originados por la crisis económica de 1914; reacciones a su postura clerical recalcitrante ante la escalada de disputas ideológicas que precedieron y sucedieron a la Reforma Universitaria de 1918-, ese comportamiento conspiró, por su influencia negativa sobre la opinión ciudadana y sobre las posibilidades de acercamiento con los radicales disidentes, contra el desempeño electoral del oficialismo que perdía el gobierno en los comicios efectuados a fines de 1918.30

Cabe preguntar si los parlamentarios pertenecientes a un mismo partido seguían o no estrategias unitarias en la legislatura. También es pertinente indagar si el ejecutivo y los legisladores oficialistas defendían posiciones comunes. Una primera aproximación a esta cuestión debe considerar los alineamientos internos de los representantes. Al respecto, si el oficialismo controlaba las cámaras, la mayoría legislativa no siempre pertenecía a la liga interna del primer mandatario. Ello se debía a varios factores. En primer lugar, como ahora en la designación de candidatos a cargos ejecutivos influía mucho más la posibilidad de alcanzar el triunfo electoral que el peso partidario del postulante, el oficialismo no siempre llevaba a la legislatura a una mayoría de aliados internos del gobernador. Por ejemplo, al promediar la segunda década del siglo XX, fuentes roquistas afirmaban que, de un total de 57 diputados y senadores, sólo siete respondían al círculo más cercano al gobernador demócrata Ramón J. Cárcano (1913-1916). Ese número era inferior al de legisladores alineados en otras ligas oficialistas pues, según la misma fuente, dieciséis se alineaban con Julio A. Roca (h.) y once con el anterior gobernador

30 AHL, Diputados (24/10 al 6/11/1916); Revista Argentina de Ciencias Políticas, Volumen 14, 1917, pp. 314-315, 427-428 y 680; Volumen 15, 1917, pp. 346-347 y 366; y Gardenia Vidal (1995: 64-66). 
Félix T. Garzón. ${ }^{11}$

Ello se combinaba, para reducir aún más la incidencia del ejecutivo, con la influencia de los gobernadores salientes sobre los órganos partidarios, donde construían mayorías adictas a su liderazgo, a menudo opuesto al del primer mandatario en ejercicio. Si bien los gobernadores salientes podían ceder a rivales internos la candidatura gubernativa, muchas veces ante el imperativo de obtener la aprobación del electorado, pretendían continuar influyendo en los juegos de poder mediante el control de algunos recursos estratégicos. Durante el gobierno de Julio A. Roca (h) (1922-1925), también demócrata, los seguidores de su antecesor y adversario interno Rafael Núñez (1919-1921), ahora presidente del partido oficialista, tenían mayoría en los cuerpos partidarios que definían candidaturas. En 1924, por ejemplo, en la convención partidaria provincial, los nuñistas contaban con el apoyo de cincuenta delegados contra sólo dieciséis alineados con la camarilla liderada por el ministro de gobierno Guillermo Rothe, aliado de Roca. Mientras que, durante el segundo gobierno de Ramón J. Cárcano (1925-1928), era designado presidente partidario el ex gobernador Roca, también distanciado de su sucesor. A partir de su incidencia sobre las decisiones partidarias, Roca impedía, en 1926, algunas postulaciones de dirigentes alineados con el gobernador. ${ }^{2}$ Los ejemplos citados muestran que, de ese modo, el control de las nominaciones legislativas podía quedar en manos de rivales del gobernador.

La pertenencia a diversas ligas no impedía, generalmente, el voto en bloque dentro de las cámaras, pues la novedosa polarización entre dos fuerzas politicas -radicales y demócratas- fortalecía la disciplina partidaria. Esa tendencia era limitada por la persistencia, entre los parlamentarios, de una valoración positiva respecto a la autonomía del electo, y por la subsistente, aunque menos marcada que antes de 1912, inestabilidad de algunos alineamientos. Respecto a lo primero, puede mencionarse el ejemplo del diputado Mariano Cevallos, dirigente con ascendiente en el centro sur de la provincia, quien sostenía, en 1914, que había votado a los dos últimos

31 AGN, Fondo Julio A. Roca (h.), s./f.

32 AGN, Fondo Julio A. Roca (h.), febrero de 1926; La Voz del Interior (18 al 26/o2 y 6/11/1924; 3 y 6/02/1926). 
oficialismos pero que en la cámara actuaría con independencia. 33

La tendencia a la disciplina partidaria fue más el producto de un proceso que algo dado tras la reforma electoral. En 1914, por ejemplo, el radicalismo pedía los asientos de la izquierda en el recinto parlamentario para poder actuar como bloque, pero el número de asientos solicitados era menor al de legisladores que habían sido electos con el patrocinio de ese partido.34 Tal tendencia coexistió, además, con cruces de alianzas entre legisladores oficialistas y opositores en el tratamiento de diversos asuntos. Al respecto, los diarios de sesiones de las cámaras muestran muchas votaciones en que legisladores oficialistas apoyaban, contra la opinión de sus correligionarios, proyectos de parlamentarios opositores, o se oponían, junto con sus rivales, a proyectos del ejecutivo. La división de la bancada opositora también se producía en algunas votaciones, cuando algunos de sus miembros apoyaban mociones oficialistas. Todo ello no alteraba, generalmente, la mayoría parlamentaria, pero había ocasiones en que la minoría conseguía revertir resultados de votaciones.

Los cruces de alianzas entre representantes de fuerzas políticas rivales eran mayores si se discutían temas que afectaban convicciones ideológicas o intereses sectoriales y/o regionales. Por ejemplo, al debatirse en la cámara baja la iniciativa gubernamental de incluir, en el presupuesto de 1916, salarios para maestros de religión, la oposición y la mayoría demócrata apoyaban la propuesta, resistida sólo por tres diputados oficialistas. Un proyecto de ley que en 1914 acotaba a la profesión de abogado la facultad de intervenir en asuntos legales relativos a herencias, era apoyado por legisladores que, más allá de sus alineamientos, eran profesionales del derecho, y era resistido por radicales y demócratas que ejercían otras profesiones, que hasta entonces podían ocuparse de esas cuestiones. Otro debate parlamentario que cruzaba intereses sectoriales y regionales era el de trasladar, en 1916, tribunales judiciales desde localidades del interior a la capital, pues recibía el apoyo de legisladores oficialistas y opositores que ejercían la profesión de abogado, y era rechazado por representantes de las regiones afectadas por el traslado, independientemente de

33 AHL, Diputados (28/12/1914). Las discusiones en torno a la independencia del legislador y a la conformación de bloques parlamentarios en esa etapa en Argentina, han sido analizadas por Ana Virginia Persello (2004: 97-100).

34 AHL, Diputados (5/05/1914). 
sus alineamientos partidarios. 35 Además, legisladores oficialistas y opositores se unían, cada vez que se trataba la ley de presupuesto, en la demanda de mayores asignaciones para los distritos que representaban.

Aún con mayoría legislativa, el apoyo a las iniciativas del ejecutivo no era automático. El gobernador Cárcano, líder de una liga oficialista minoritaria, afrontó su primer mandato, entre 1913 y 1916, sin que los legisladores, mayoritariamente alineados en su partido, aprobaran el presupuesto provincial. $\mathrm{Su}$ gobierno debió responder, además, a interpelaciones promovidas por radicales o por demócratas disidentes. El resultado de esas interpelaciones favorecía al ejecutivo. En 1914, por ejemplo, tras una interpelación promovida por diputados oficialistas, alineados con el ex gobernador Félix T. Garzón, en torno al desempeño de funcionarios policiales, se rechazaba por amplia mayoría una moción de que la cámara se declarara inconforme. Al año siguiente, eran derrotadas mociones similares del radicalismo respecto a la gestión de gobierno y a la comisión de irregularidades electorales por parte de autoridades policiales. Pero el rechazo de las mociones opositoras no siempre se efectuaba en los términos pretendidos por los legisladores cercanos al gobernador. Por ejemplo, tras una interpelación en torno a la ejecución de algunas partidas presupuestarias, se rechazaba la moción radical de exhortar al gobierno a encuadrar sus gastos dentro del presupuesto vigente, pero una parte del oficialismo se unía con la oposición para aprobar una declaración que, aunque mas moderada, era resistida por legisladores cercanos a Cárcano. ${ }^{36}$

La facilidad con que Cárcano logró la aprobación de proyectos que despertaban polémicas permite inferir, sin embargo, que las situaciones generadas con el presupuesto y con alguna interpelación no obedecían a un sistemático obstruccionismo legislativo. Un ejemplo es el de la reforma de la ley orgánica municipal, sancionada en 1914. A pesar de la cerrada oposición del radicalismo, no sólo fue aprobado el contenido de ese proyecto del ejecutivo sin modificaciones sustantivas, sino que el procedimiento empleado en la cámara baja, donde en una maratónica sesión se trató todo el articulado a pesar de una moción opositora de postergación, es indicativo de cierta sumisión parlamentaria a las prioridades del gobierno. Un segundo ejemplo es el del

\footnotetext{
35 AHL, Diputados (11 y 14/05/1914; 23/08/1915; 19/08/1916).

36 AHL, Diputados (4 y 8/06/1914; y 15/07 al 5/08/1915).
} 
alineamiento mayoritario de los representantes oficialistas cuando el primer mandatario vetó una ley -que establecía un conjunto de subsidios a entidades benéficas-sancionada por las cámaras en 1913.37

En temas estrictamente ligados con las disputas de poder, los legisladores oficialistas podían votar divididos, en especial cuando los conflictos intrapartidarios conducían a deserciones de camarillas. En 1916, ante la designación de senador nacional, atributo de ambas cámaras legislativas reunidas en asamblea, los demócratas votaban divididos a pesar de que la convención partidaria había nominado un candidato. El grupo, minoritario pero no insignificante, que desobedecía el mandato partidario, se alineaba con el ex gobernador Félix T. Garzón y meses más tarde abandonaba las filas demócratas. La mayoría parlamentaria respetaba la decisión partidaria, pero tras un proceso de delicadas negociaciones, a juzgar por la correspondencia entre dirigentes oficialistas en la etapa previa a esa designación. La dificultad para acordar posiciones entre legisladores oficialistas crecía si mermaba la presencia parlamentaria de fuerzas rivales. Entre 1921 y 1924, cuando los demócratas impusieron una aplastante mayoría debido a la abstención electoral del radicalismo, la disputa entre miembros del partido gobernante se trasladó a las cámaras. Con una menor cantidad de legisladores alineados con el gobernador que con sus adversarios internos, se potenció la capacidad del parlamento local de entorpecer al gobierno. En 1924, por ejemplo, los legisladores oficialistas no unificaban posiciones ante la dimisión que, generada por un conflicto partidario, había presentado el gobernador Julio A. Roca (h.), cuyos aliados se veían obligados a dejar sin quórum a la asamblea legislativa encargada de tratar el asunto. ${ }^{38}$

Luego de 1912, la posición de los legisladores oficialistas en las cámaras fluctuaba entre la condición de bloque mayoritario y el papel de fuerza minoritaria. La convergencia entre el ejecutivo y la mayoría parlamentaria no implicaba, necesariamente, que ésta respondiera a la liga interna del gobernador, quien muchas veces no controlaba los órganos partidarios a cargo

37 AHL, Diputados (1/o9/1913; y 28/08/1914).

38 AGN, Fondo Julio A. Roca (h.), febrero de 1916; Revista Argentina de Ciencias Políticas, Volumen 11, 1916, p. 567; La Voz del Interior (21 al 26/02/1924). 
de nominar candidatos. En esas circunstancias, hubo debates parlamentarios, algunos de ellos directamente vinculados con la preservación de espacios de poder, en que se resintió la posibilidad de unificar a los legisladores oficialistas.

\section{A modo de síntesis}

Antes de 1912, entre cuerpos parlamentarios y gobiernos se estableció una relación de mediana autonomía y mediana subordinación. Los órganos legislativos eran instancias capaces de actuar con independencia de los gobiernos y de condicionar sus decisiones, pero el gobierno tenía herramientas para disciplinar a los representantes parlamentarios. Esos expedientes podían fracasar en casos individuales, pero generalmente alcanzaban para contar con una amplia mayoría oficialista. Sin embargo, aunque el obstruccionismo legislativo fue excepcional en Córdoba, tales excepciones ocurrieron, pues en diferentes momentos hubo mayorías opositoras decididas a desplazar al gobernador o a obstruir seriamente su gestión; o mayorías oficialistas pero independientes del gobernador en decisiones que podían generar crisis en las alianzas gobernantes. Algunos factores que, aislados o combinados, conformaban escenarios favorables para que los cuerpos legislativos tomaran distancia del gobierno, eran la limitación temporal de los cargos ejecutivos, pues los gobernadores salientes podían conformar legislaturas que luego confrontaran con sus sucesores; la inestabilidad de las alianzas entre las camarillas, pues la ruptura de compromisos podía distanciar al titular del ejecutivo de una mayoría de legisladores que aquel había contribuido a ubicar en sus escaños; escisiones entre el oficialismo nacional y el provincial, hecho que alentaba a muchos legisladores a cambiar de alineamiento con el fin de reacomodarse ante el posible desplazamiento de administraciones provinciales vulnerables a la ofensiva del gobierno federal.

Tras la reforma electoral de 1912, la relación entre gobiernos y parlamentos fue modificada por una más nutrida presencia de la oposición en las cámaras, presencia que, en ocasiones, se traducía en alineamientos divergentes entre el ejecutivo y la mayoría legislativa. Si el oficialismo controlaba las cámaras, la mayoría legislativa no siempre pertenecía a la liga interna del primer mandatario. Por ello, aún con mayoría legislativa, el apoyo a 
las iniciativas del ejecutivo no siempre era automático, incluso en temas estrictamente relacionados con disputas de poder.

\section{Bibliografía}

ALONSO, Paula. Entre la revolución y las urnas. Los orígenes de la Unión Cívica Radical y la política argentina en los años '9o. Buenos Aires: Editorial Sudamericana, Universidad de San Andrés, 2000.

ANSALDI, Waldo. Frívola y casquivana, mano de hierro en guante de seda. Una propuesta para conceptualizar el término oligarquía en América Latina. Montevideo, Cuadernos de CLAEH, N 61, 1992.

ARTOLA, Miguel. Partidos y programas políticos, 1808-1936. I. Los partidos políticos. Madrid: Alianza Editorial, 1991.

BOTANA, Natalio. El orden conservador. La política argentina entre 1880 y 1916. Buenos Aires: Sudamericana, 1994.

CÁRCANO, Ramón J. Mis primeros ochenta años. Buenos Aires: Pampa y Cielo, 1945 .

CARMAGNANI, Marcello. Estado y mercado. La economía pública del liberalismo mexicano, 1850-1911. México: Fondo de Cultura Económica, El Colegio de México, 1994.

CARVALHO, José Murilo de. Teatro de sombras. A politica imperial. Río de Janeiro: Edições Vértice e Impeij, 1987.

FERRARI, Marcela. Los políticos en la república radical. Prácticas políticas y construcción de poder. Buenos Aires: Siglo XXI, 2008.

FORD, Lacy K. Jr. Origins of Southern radicalism. The South Carolina Upcountry, 180o-186o. New York, Oxford: Oxford University Press, 1988.

FORD, Lacy K. Jr. Rednecks and merchants: economic developmentand social tensions in the South Carolina Upcountry, 1865-1900. The journal of American History, Vol 71, N² 2, September (Bloomington, Indiana), 1984, pp. 294-317.

GUERRA, Francois-Xavier. Las elecciones legislativas de la revolución mexicana. 1912. Revista Mexicana de Sociología, México, UNAM, Instituto de Investigaciones Sociales, Año LII, N² 2, Abril/Junio de 1994, pp. 248-260.

HOLT, Thomas. Black over white. Negro political leadership in South Carolina during reconstruction. Urbana y Chicago: University of Illinois Press, 1979.

KRESS, Lee Bruce. Julio A. Roca and Argentina, 1880-1886: a political and economic study. Tesis de doctorado. Columbia University, 1972.

LUNA ARGUDÍN, María Leonila. El Congreso de la Unión y las transformaciones del liberalismo y federalismo mexicanos, 1857-1910. Tesis de doctorado en Historia. México: El Colegio de México, 1971.

MALAMUD, Carlos (ed.). Partidos políticos y elecciones en América Latina y la Península Ibérica, 1850-1930. Madrid: Instituto Universitario Ortega y Gasset, 1995 .

(coord.). Legitimidad, representación y alternancia en España y 
América Latina: las reformas electorales (1880-1930). México: El Colegio de México, Fideicomiso Historia de las Américas, Fondo de Cultura Económica, 2000.

MANSILLA, César L. Los partidos provinciales. Buenos Aires: Centro Editor de América Latina, 1983.

MELO, Carlos R. Los Partidos políticos argentinos. Córdoba: Universidad Nacional de Córdoba, 1970.

MOYANO, Javier. Régimen oligárquico y transformación del sistema político. El caso de las élites conservadoras cordobesas de Argentina. 189o-1930. Tesis de doctorado en Historia. México: El Colegio de México, 2006.

PERSELLO, Ana Virginia. El Partido Radical. Gobierno y oposición, 1916-1943. Buenos Aires: Siglo XXI Editores Argentina, 2004.

POTTER, Anne Louise. Political institutions, political decay and the Argentine crisis of 1930. Stanford: Stanford University, 1979.

SÁBATO, Hilda (coord.). Ciudadanía política y formación de las naciones. Perspectivas históricas de América Latina. México: El Colegio de México, Fideicomiso Historia de las Américas, Fondo de Cultura Económica, 1999.

y LETTIERI, Alberto (comp.). La vida política en la Argentina del siglo XIX. Armas, votos y voces. Buenos Aires: Fondo de Cultura Económica, 2003.

SÁNCHEZ, Emilio. Del pasado cordobés en la vida argentina. Córdoba: Biffignandi, 1986.

SMITH, Peter. Argentina and the failure of democracy. Conflict among political elites. 1904-1955. Wisconsin: The University of Wisconsin Press, 1974.

SUPPLE, Joan. Provincial elites and economic transformation of Mendoza, Argentina, 1880-1914. Austin: The University of Texas at Austin, 1988.

VERA DE FLACHS, Cristina. Ambrosio Olmos: inicio provisorio y fin trágico. Córdoba: Poder Legislativo, 1986.

VIDAL, Gardenia. Radicalismo de Córdoba. 1912-193o. Los grupos internos: alianzas, conflictos, ideas, actores. Córdoba: Universidad Nacional de Córdoba, 1995 .

Colaboração recebida em 01/12/2008 e aprovada em 10/12/2008. 